\title{
Measurement of gravitational acceleration with the leak tank method
}

\author{
Reliusman Dachi ${ }^{1}$, Ikhsan Setiawan ${ }^{2}$ \\ Department of Physics, Faculty of Mathematics and Natural Sciences, Universitas Gadjah Mada \\ Sekip Utara BLS 21 Yogyakarta 55281 Indonesia \\ ${ }^{1}$ E-mail : reliusman.dachi@mail.ugm.ac.id, ${ }^{2}$ ikhsan_s@ugm.ac.id
}

Received 10 August 2017, Revised 18 January 2018, Published 31 March 2018

\begin{abstract}
An experimental device of the mechanics of tank draining under gravity has been constructed. It mainly consists of a cylindrical tank with a circular orifice at the center bottom of the tank. The inner radius of the tank is $134 \mathrm{~mm}$, while there are seven variations of orifice radius, those are 2.25 $\mathrm{mm}, 2.50 \mathrm{~mm}, 3.00 \mathrm{~mm}, 3.50 \mathrm{~mm}, 4.00 \mathrm{~mm}, 5.00 \mathrm{~mm}$, and $6.00 \mathrm{~mm}$. The tank is filled by water which is then allowed to flow out throuh the orifice. This experiment can be used to measure the value of gravitational acceleration $(g)$ on the experiment location. We call this method as the leak tank method. The measurement of $g$ is carried out by measuring the total time to drain the tank from $300 \mathrm{~mm}$ initial height of water surface inside the tank for various orifice radius. It is found in this experiment that $g=(9.89 \pm$ $0.03) \mathrm{m} / \mathrm{s}^{2}$. This result is good enough because it is almost the same as the conventional standar value of $9.80665 \mathrm{~m} / \mathrm{s}^{2}$ with discrepancy of around $0.85 \%$. It indicates that the leak tank method which is described in this paper can be used to estimate the gravitational acceleration value with a good result.
\end{abstract}

Keywords: Gravitational acceleration, tank draining, the leak tank method

\section{INTRODUCTION}

Mechanics of draining water from the tank under gravity is a theme that is not new anymore, but it has a lot of complexity in it (Joye and Barrett, 2003). When the water in the tank removed through a hole, Torricelli equation can be used to describe the discharge and flow rate (de Nevers, 1991).

Hart and Sommerfeld (1955) has conducted a mathematical analysis on the time needed to discharge through a restricted orifice of a tank. Hart and Sommerfeld said that there are two fundamental equations which are important in solving the mechanical dewatering of the open tank, those are the equation of the conservation of mass and the equation of the debit conservation, derived based on the Bernoulli equation. The equations are

$$
A \frac{d h}{d t}=-v A_{0}
$$

and 


$$
v=C_{d} \sqrt{2 g h}
$$

where $A$ and $A_{0}$ are cross-sectional area of the tank and the orifice, respectively, $v$ is the velocity of the water flow inside the tank, $h$ is the height of the water surface inside the tank relative to the orifice location, $C_{d}$ is the discharge coefficient, and $g$ is the gravitational acceleration. The discharge coefficient is the ratio between the real flow rate $\left(Q_{0}\right)$ through the orifice with the theoretical flow rate which is mathematically written as (Soedradjat, 1983):

$$
C_{d}=\frac{Q_{o}}{A_{0} \sqrt{2 g h}}
$$

If $C_{d}=1$, then the equation (3) in accordance with the Torricelli theorem (Subarrao,2012).

In several studies that have been done, discharge coefficient was usually taken as 0.61 for Reynolds numbers greater than about 10,000, but sometimes the discharge coefficient of 0.63 was used (Wilkes, 1999). The discharge coefficient value usually depends on the value of the Reynolds number, pressure on the water surface, and the shape of the hole edge (Perry and Green, 1984). For the water flow from the tank through a small hole, Foster (1981) reported that the debit coefficient for the circular hole is 0.98. In addition, Joye and Barrett (2003) stated that the total time for draining water from the tank through a hole without additional pipeline can be obtained accurately only when a proper debit coefficient of discharge $\left(C_{d}\right)$ is used, and this is true for both laminar and turbulent flow. They reported that $C_{d}=0.8$ for a hole with a short additional pipe, with ratio of additional pipe length $(L)$ and pipe diameter $(d)$ of $L / d=$ 3.0.

In the experiment of the mechanics of water draining of a tank, the water inside the tank is generally influenced not only by gravity but also by a force (or pressure) imposed on the surface of the water (Joye and Barrett, 2003). In addition, the hole that serves as the water outlet can be located on the wall or at the bottom of the tank. Moreover, the hole can be situated as the hole as is (orifice situation) or with additional pipe which is jutting out from the wall or bottom of the tank. Furthermore, the process of water draining may occur quickly or slowly depending on the ratio of the crosssectional areas of the tank and the hole $\left(A_{\mathrm{T}} / A_{\mathrm{H}}\right)$. In this study, the water outlet is located at the bottom of the tank without additional pipe, while the draining process is slow.

In the mechanics of the tank draining, the experimental results will be close to the theoretical results if the ratio of the cross-sectional area of the tank and the hole area $\left(A_{\mathrm{T}} / A_{\mathrm{H}}\right)$ is greater than or equal to 722 (Libbi, 2003). For the area ratio smaller than 722 , Libbi mentioned that the acceleration of fluid particles can no longer be considered constant and can not be negligible compared to the acceleration of gravity. This empirical value was obtained by Libbi in his experiment that used a tank with a 
diameter of $292.1 \mathrm{~mm}$ and with hole diameters of $5.33 \mathrm{~mm}, 6.68 \mathrm{~mm}, 9.45 \mathrm{~mm}$, and $10.87 \mathrm{~mm}$. However, the Libbi's experiments has not been able to confirm the information obtained from Sabersky et al. (1971) that theoretically the above approach will still valid until the ratio is as low as 100 .

Based on the desciption above, the authors intends to construct an experimental device on the mechanics of tank draining under the influence of the earth's gravity and then test the device to measure the gravitational acceleration on the experiment location. It will be investigated whether this measurement method can give fairly good result in measuring the value of the acceleration of gravity. We call this technique as the leak tank method.

\section{THEORY}

Consider a vertical cylindrical tank with a small circular hole in the center of the bottom of the tank. Assume that $A_{\mathrm{T}}$ is the cross-sectional area of the tank with radius $R_{\mathrm{T}}, A_{\mathrm{H}}$ is the area of the hole with radius $R_{\mathrm{H}}, h_{0}$ is the initial height of the water surface inside the tank relative to bottome of the tank, that is the height at time $t=0, h(t)$ is the height of water at time $t$ afterwards, and $t_{\text {drain }}$ is the time of draining the tank until the whole water inside the tank is run out. By applying the law of conservation of mass in an open system, then the equations that govern the water level in the tank as a function of time is given by (Libii, 2013)

$$
h\left(g+\frac{d^{2} h}{d t^{2}}\right)=\frac{1}{2}\left(\frac{d h}{d t}\right)^{2}\left[\left(\frac{R_{\mathrm{T}}}{R_{\mathrm{H}}}\right)^{4}-1\right]
$$

For the case of slow draining, the acceleration of the water surface $\left(d^{2} h / d t^{2}\right)$ is very small compared to the gravitational acceleration so that it can be ignored in the Eq. (4). Then, the folowing equation can be obtained

$$
\frac{d h}{d t}=-\frac{(2 g h)^{1 / 2}}{\left[\left(\frac{R_{\mathrm{T}}}{R_{\mathrm{H}}}\right)^{4}-1\right]^{1 / 2}} .
$$

with the negative sign on the right-hand side indicates that the height $h$ decreases with time. The total time required to drain the tank can be found by integrating the Eq. (5), that is

$$
t_{\text {drain }}=\left(\frac{2 h_{0}}{g}\right)^{1 / 2}\left[\left(\frac{R_{\mathrm{T}}}{R_{\mathrm{H}}}\right)^{4}-1\right]^{1 / 2} .
$$

Based on the Eq. (6), by varying the hole radius $R_{\mathrm{H}}$ and measuring the draining time $t_{\mathrm{drain}}$, the value of gravitational acceleration $g$ can obtained from the slope $(m)$ of the plot of $t_{\mathrm{drain}}^{2}$ versus $\left(R_{\mathrm{T}} / R_{\mathrm{L}}\right)^{4}-1$, that is 


$$
g=\frac{2 h_{0}}{m}
$$

\section{EXPERIMENTAL METHOD}

The experimental apparatus of the mechanics of tank draining that have been made and used in this experiment are shown in Figure 1. The tank is made of two PVC (Polyvinyl Chloride) sockets (Rucika DV-DS type) with nominal diameter of 10 inches and inner radius of $R_{\mathrm{T}}=(134 \pm 2) \mathrm{mm}$. The total height of tank is $480 \mathrm{~mm}$. A transparan (acrylic) millimeter scale is assembled on the tank wall to measure the water level inside the tank as can be seen in Fig. 1(a). A circular acrylic plate with thickness of $6 \mathrm{~mm}$ is used to cover the bottom of the tank that serves as the base of the tank. This plate has a threaded circular hole in the middle. A small and threaded circular plate with a hole can be installed at the previous hole. Seven small circular plates with different hole diameters that are used in this experiment are shown in Fig. 1(b). The radius of these holes and the inner radius of the tank are listed in Table 1. The hole is closed by a rubber plug before the tank is filled with water.

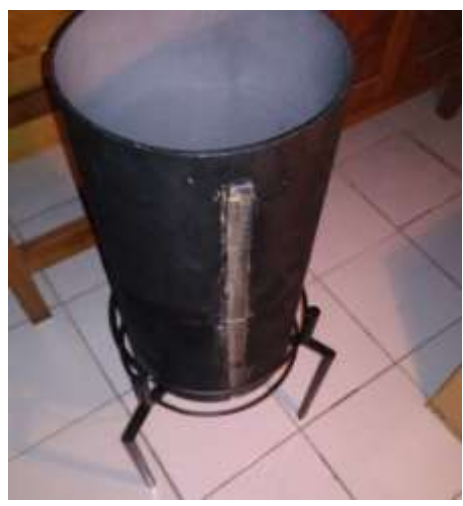

(a)

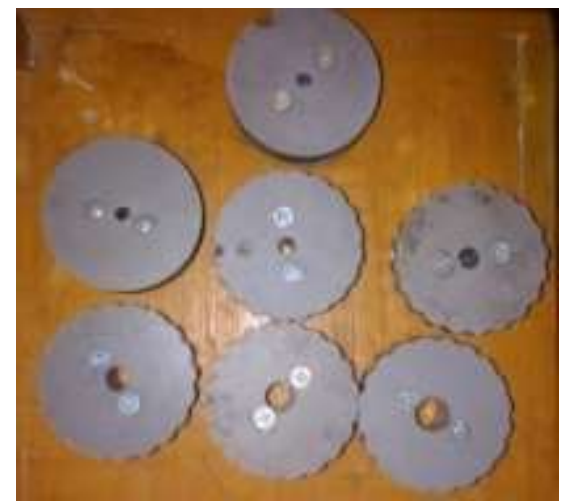

(b)

Figure 1. (a) The water tank equipped with a transparent vertical scale on the wall. (b) Plug-stoppers with various radius of water outlet holes.

Fig. 1 shows the schematic diagram of the experimental setup. The tank is put on an iron stand. A bucket is placed under the stand to collect the water which is flowing out of the tank through the hole at the bottom of tank. In this experiment, the initial height $\left(h_{0}\right)$ of the water inside the tank is $(300 \pm 1) \mathrm{mm}$. The experiment is performed by measuring the draining time $\left(t_{\mathrm{drain}}\right)$ of tank with initial water height $\left(h_{0}\right)$ inside the tank for various hole radius $\left(R_{\mathrm{H}}\right)$ by using a stopwatch. The experimental data is then plot as $t^{2}$ Total versus $\left[\left(R_{\mathrm{T}} / R_{\mathrm{L}}\right)^{4}-1\right]$ according to the equation

$$
t_{\text {drain }}^{2}=\left(\frac{2 h_{0}}{g}\right)\left[\left(\frac{R_{\mathrm{T}}}{R_{\mathrm{H}}}\right)^{4}-1\right]
$$


and the value of gravitational acceleration is obtained from the slope of the graph (see Eq. (7)).

Table 1. Summary of experimental equipments size.

\begin{tabular}{lc}
\hline \multicolumn{1}{c}{ Quantities } & Size $(\mathrm{mm})$ \\
\hline Inner radius of the tank $\left(R_{\mathrm{T}}\right)$ & $134 \pm 2$ \\
\hline High of the tank & $480 \pm 1$ \\
\hline & $2.25 \pm 0.01$ \\
& $2.50 \pm 0.01$ \\
Radius of the holes $\left(R_{\mathrm{H}}\right)$ & $3.00 \pm 0.01$ \\
& $3.50 \pm 0.01$ \\
& $4.00 \pm 0.01$ \\
& $5.00 \pm 0.01$ \\
Initial height of water $\left(h_{0}\right)$ & $6.00 \pm 0.01$ \\
\hline
\end{tabular}

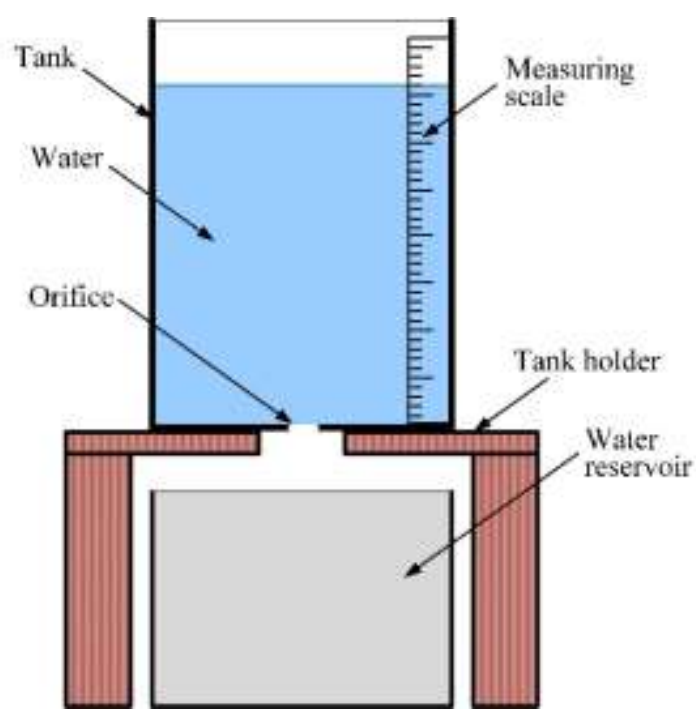

Gambar 2. Schematic diagram of the experimental setup.

\section{RESULTS AND DISCUSSION}

The experimental result is shown in Fig. 3 which is plotted based on the Eq. (8). It can be seen that the experimental data follow a linear pattern very well. By using the linear regression analysis, it is obtained a linear equation that represents the experimental data points, that is $y=0.0606 x-934.6$, where $y$ represents $t_{\mathrm{drain}}^{2}$ and $x$ 
represents $\left(R_{\mathrm{T}} / R_{\mathrm{L}}\right)^{4}-1$. From this equation then the value of the gravitational acceleration is calculated, giving

$$
g=(9.89 \pm 0.03) \mathrm{m} / \mathrm{s}^{2}
$$

The results is very good because it is very close to the conventional standard value of gravitational acceleration of $9.80665 \mathrm{~m} / \mathrm{s}^{2,}$ with deviation only about $0.85 \%$.

Based on the Eq. (7), the uncertainty of the gravitational acceleration is approximately calculated as

$$
\Delta g=\left(\frac{\Delta h_{0}}{h_{0}}+\frac{\Delta m}{m}\right) g
$$

where $\Delta h_{0}$ is the uncertainty of the initial height of water and $\Delta m$ is the uncertainty of the slope of the graph in Fig. 3. Because the data points in Fig. 3 follows the straight line well, then the relative uncertainty of the slope $(\Delta m / m)$ is small enough. Therefore, in this case, the unccertainty $\Delta g$ is more contributed by the uncertainty in the initial height $\Delta h_{0}$ of water inside the tank. To reduce the effect of the uncertainty in the initial height of water, that is reducing the relative error $\left(\Delta h_{0} / h_{0}\right)$ in the initial height of water, can be accomplished by increasing the initial height of water (increasing the $h_{0}$ ) and improving the accuracy in determining the initial height of water (decreasing the $\Delta h_{0}$ ). Of course, increasing $h_{0}$ requires a long (high) enough tank.

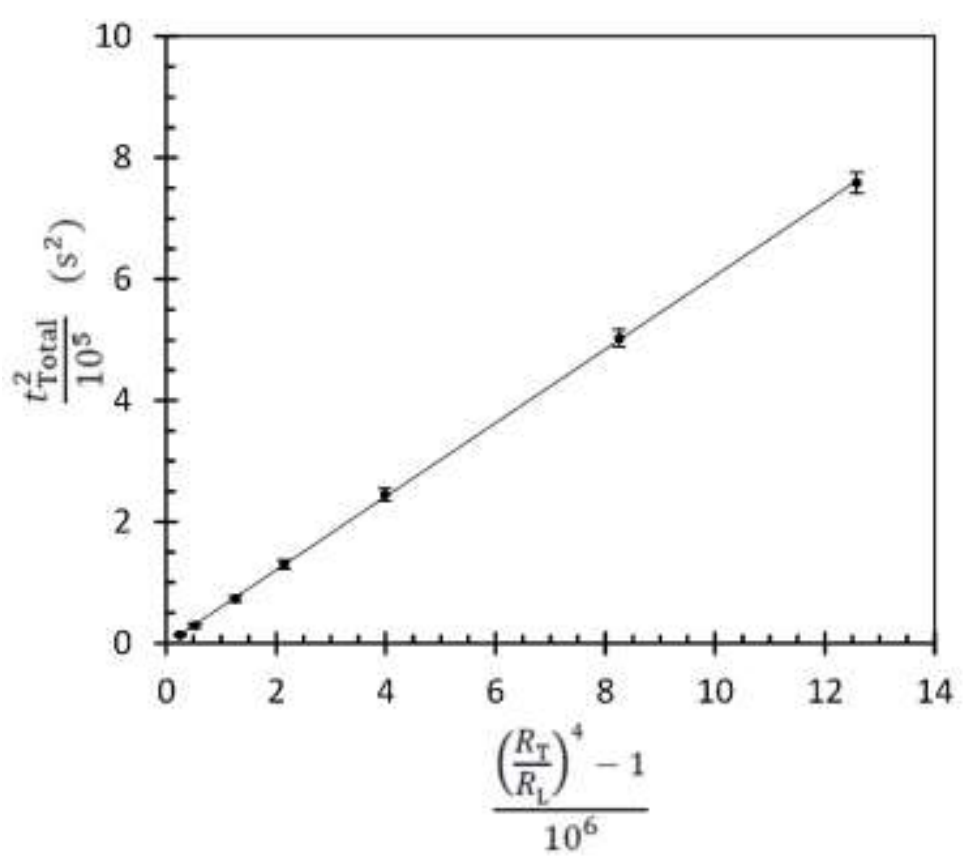

Gambar 3. The graph of experimental data along a linear line with the equation $y=$ $0.0606 x-934.6$ with y represents $t_{\text {Total }}^{2}$ and $x$ represent $\left(R_{\mathrm{T}} / R_{\mathrm{L}}\right)^{4}-1$. 
The main difficulty encountered in this experiment is the difficulty in determining the time when the water has completely been drained from the tank. Sometimes, there is still water left in the tank because the tank bottom is flat or slightly slanting. In addition, the water is still dripping from the hole and the interval between each drop is relatively long, making it difficult to determine when the stopwatch should be turned off. Those things mentioned aboved are thought to be the cause of the graph line in Figure 3 does not intersect the point $(0,0)$ as it was supposed according to equation (8).

Futhermore, one drawback of this method is the occurrence of vortex (turbulence) above the exit hole of the water when the water is running low, whereas the equations used and described above is obtained with the assumption that the water in the tank moves down with laminar flow. In general, however, the results of this experiment showed that the leaking tank method described in this paper can be used to estimate the gravitational acceleration with a good result.

\section{CONCLUSION}

Experiment of draining of a tank by gravity can be used to measure or estimate the value of the gravitational acceleration with a good result. We call this technique as the leak tank method. Testing on this method provides a measurement value of the gravitational acceleration of $g=(9.89 \pm 0.03) \mathrm{m} / \mathrm{s}^{2}$, which is differ only about $0.85 \%$ of the conventional standard value of $9.80665 \mathrm{~m} / \mathrm{s}^{2}$.

\section{RECOMMENDATION (FUTURE WORK)}

Further experiment related to the measurement of the gravitational acceleration with the leak tank method is an experiment with a higer initial height of the water level inside the tank. As mentioned above, the greater the initial height of the water level the smaller the relative uncertainty in the initial height of the water level which in turn resulting in the smaller uncertainty in the gravitational acceleration, so that the measurement result is more precise.

Moreover, to overcome difficulty in determining the time when the water inside the tank is completely exhausted, the experiment can be done by measuring the time $t$ required by the water level moves down from the initial height $h_{0}$ to a final height of $h_{t}$ whici is not zero, that is not until the water completely run out. In this case, the equation to be used is obtained from the integration of the equation (5) with time integration limit from 0 to $t$, and height integration limit is from $h_{0}$ to $h_{t}$, that is

$$
h_{0}^{1 / 2}-h_{t}^{1 / 2}=\frac{(g / 2)^{1 / 2}}{\left[\left(\frac{R_{\mathrm{T}}}{R_{\mathrm{L}}}\right)^{4}-1\right]^{1 / 2}} t .
$$


The value of the gravitational acceleration $(g)$ can be obtained from the slope of the plot of $h_{0}^{1 / 2}-h_{t}^{1 / 2}$ versus $t$.

\section{REFERENCES}

de Nevers, N. (1991). Fluid Mechanics for Chemical Engineers, Second Edition.McGraw-Hill, New York, 163-166.

Joye, D. D. dan Barret, B.C. (2003). The tank drainage problem revisited: Do these equations actually work?.The Canadian J. Chem. Eng, Vol. 81, 1052-1057.

Libii, J. N. (2003). Mechanics of slow draining of a large tank under gravity.Am. J. Phys, Vol. 71, 1204-1207.

P. W. Hart and J. T. Sommerfeld.(1995). Expression for Gravity Draining of Annular and Toroidal Containers.Process Safety Progress, 238-243.

Perry R.H. and D.W. Green.(1984) Perry's Chemical Engineers Handbook 6th Edition.McGraw-Hill, New York,5-27.

S. Soedradjat A. (1983).Mekanika Fluida dan Hidrolik, Nova, Bandung, 135-152.

Subbarao, CH. V. (2012). Review On Efflux Time.Int. J. Chem. Sci., 1255-1270.

T. C. Foster.(1981). Time Required to Empty a Vessel.Chem. Eng., 105.

Wilkes, J.O. (1999).Fluid Mechanics for Chemical Engineers.Prentice-Hall PTR,68. 